\title{
Impact of Time of Weeding on Tobacco (Nicotiana tabacum) Growth and Yield
}

\author{
Mashezha Ian, ${ }^{1}$ Rukuni Dzingai, ${ }^{2}$ Manyangarirwa Walter, ${ }^{1}$ and Svotwa Ezekia ${ }^{2}$ \\ ${ }^{1}$ Africa University, P.O. Box 1320, Mutare, Zimbabwe \\ ${ }^{2}$ Tobacco Research Board, Kutsaga Farm, P.O. Box 1909, Harare, Zimbabwe
}

Correspondence should be addressed to Mashezha Ian; ian.mashezha@gmail.com

Received 3 July 2013; Accepted 18 August 2013

Academic Editors: G. M. Dal Bello, C. H. Kao, and M.-J. Simard

Copyright (c) 2013 Mashezha Ian et al. This is an open access article distributed under the Creative Commons Attribution License, which permits unrestricted use, distribution, and reproduction in any medium, provided the original work is properly cited.

An experiment laid in a Randomized Complete Block Design with 4 blocks and 5 treatments, was done at Kutsaga Research Station in the 2012 / 2013 season to study the impact of time of weeding on tobacco production. The treatments comprised of different times of weed control with a weed free treatment as the control. The variables measured were stalk heights at 5, 6 and 7 weeks after planting and, leaf expansion measurements were also recorded at 9, 10 and 11 weeks. Leaf yield was measured at untying using a digital scale. Results showed that Tobacco stalk heights were affected at 5 W.A.P since significant differences $(P<0.05)$ were noted among the treatments. Suppressive effects of weeds were shown at 6 and 7 W.A.P due to effective competition $(\mathrm{RCI}>0)$ in all other treatments excluding the control. There were significant differences $(P<0.05)$ among the treatments on leaf expansion at 9,10 and 11 W.A.P. The treatment weeded at 4 W.A.P showed leaf yield that was significantly higher $($ L.S.S $=270.8)$ than the treatment weeded at 2 W.A.P. Basing on the 3 reaps recorded, time of weeding had an influence tobacco yield.

\section{Introduction}

Yield of tobacco depends on the implementation of good agronomic practices and good management of insect pests and weeds [1]. Tobacco yield loss due to weed competition is the most important factor that causes yield and quality reduction. Weed infestation of broad-leaved grasses and sedges in tobacco growing areas of Zimbabwe has reduced the primary industry productivity and profitability, and seriously limits the long-term sustainability of the crop [2]. Weeds compete directly with the desired crop for nutrients, water, light, carbon dioxide, and oxygen, and this competition significantly reduces crop yield and quality [3]. Weed suppressive impacts on tobacco are becoming a huge problem for the large commercial famers and small scale farmers. This can be largely attributed to the presence of competitive weeds and lack of capital to improve technologies of controlling them [4].

Wilson [5] estimated a $77 \%$ yield reduction and $10 \%$ quality reduction due to weed infestation in tobacco at various unknown densities of various weed species. Niell [6] also reported $12 \%$ loss due to vigorous weeds at 2-week growth stage and $64 \%$ yield loss when weeds were left in the critical weed free period of 2-6 weeks. Tobacco production at low input costs of weed management has been reported by Klingman [7] who observed a significant low gross return per unit area of the land than tobacco at high input cost of weed control. If weed management is not improved, tobacco production will not be realized, and farming in general will continue to be full of drudgery and unattractive to the younger generations [8].

Delay in weed management of aggressive weeds such as Acathospermum hispidum, Amaranthus hybridus, Cyperus rotundus, and Cyperus esculentus results in difficulties in controlling them. Their distribution in all is the primary cause of tobacco yield loss in small-holder agriculture [3]. Inevitably, the time of first weeding is spread from one to six weeks after transplanting tobacco, and the weeding operation is done once or twice but rarely three times in most field crop operations [9]. In small-holder farming environments, labor shortages are commonly encountered during the onset of the rainy season. This delay in weed control exposes the tobacco crop to weed competition effects. Effective weed control practices in such situations will require development 
of appropriate techniques and judicious weeding to cater for labor constraints [9]. High population densities due to delays in weed management will enhance the weed species with higher competitive ability. The inability to accurately predict when weeds first begin to affect yield is creating high levels of risk when relying on scheduled weed control programs [10].

This research work seeks to establish the optimum growth stage at which the tobacco is weeded for maximum growth, development, and yield. It also sought to establish the impact of delayed weeding on the weed densities in tobacco lands. It was hypothesized in this research that an appropriate timing of weed removal for maximum crop growth, development, and yield can be established. The generated information can guide practitioners to minimize the frequency of weeding, thereby reducing the cost of production without compromising yield and quality of flue cured tobacco.

\section{Materials and Methods}

The study was carried out at Kutsaga Research Station during the 2012/2013 season. The research station is in Natural Region II receiving annual rainfall of $800 \mathrm{~mm}$ to $1000 \mathrm{~mm}$ per annum. The rainfall occurs during a single rainy season from November to April [11]. The experiment was done in open field. The soils at the Research Station are sandy loams derived from granite [12]. The mean annual temperature is $21^{\circ} \mathrm{C}$ with insignificant frost occurrence in the months of June and July.

The land was ploughed using a tractor drawn plough to a depth of $38 \mathrm{~cm}$. Ridging and fertilizer applications were done on October 20, 2012. Compound C (6N : 15P : 12K) was applied at a rate of $700 \mathrm{~kg} / \mathrm{ha}$, based on soil analysis. The nematicide ethylene dibromide (EDB) was also applied at a rate of 13 litres per hectare, two weeks before planting. Tobacco seedlings of T66 variety were used. This is a slow ripening cultivar with a yield potential of more than $3500 \mathrm{~kg} / \mathrm{ha}$ cured leaf at Kutsaga. The crop was transplanted on October 25, 2012.

There were a total of 5 treatments in the trial shown in Table 1.

The experiment was laid in a Randomized Complete Block Design with 4 blocks. The design was done to block against varying soil texture, weed species distribution, weed population distribution, and slope. The experimental plots $3.6 \mathrm{~m} \times 17.92 \mathrm{~m}$ (3 rows), and the blocks, measured $18 \mathrm{~m} \times$ $17.92 \mathrm{~m}$ (15 rows). Weeding was done using hand hoe method in the plots according to treatment specification. Total weed removal was done at 8 W.A.P. Stalk heights were measured on 30 sampled plants per assessment row of each treatment using 1 meter ruler. These measurements were recorded at 5, 6, and 7 W.A.P.

Leaf expansion measurements were recorded using 1 meter rulers measuring the length and width of the leaves at 9 , 10 , and 11 W.A.P, and this was done when the crop was topped to remove apical dominance. Yield was measured after flue curing by untying the tobacco leaves and measuring weight of leaves from specified treatments at a digital scale. A general analysis of variance (ANOVA) was used in the stalk height, leaf area, and flue-cured tobacco yield using GENSTAT Ninth Edition (9.2) statistical package.
TABLE 1: Different weed control treatments applied to cultivar T66 at Kutsaga Research Station during 2012/2013 season.

\begin{tabular}{lcc}
\hline Treatment & Time of weeding & Delay period \\
\hline 1 & Standard practice (Control) & No delay \\
2 & 2 W.A.P & Delayed by 2 week \\
3 & 4 W.A.P & Delayed by 4 weeks \\
4 & 6 W.A.P & Delayed by 6 weeks \\
5 & Weeded only at 8 W.A.P & Unweeded \\
\hline
\end{tabular}

The relative competition intensity (RCI) was quantified by wide set of competition intensity of the effect size of competition $[13,14]$. The RCI measures the proportional decrease in plant performance due to weed competition. The RCI values are obtained from the following model:

$$
\text { RCI }=\frac{Y_{\text {no weed }}-Y_{\text {weed }}}{Y_{\text {no weed }}},
$$

where $Y$ is the measurement of the crop performance or of crop yield, $Y_{\text {no weed }}$ represents weed free plot and $Y_{\text {weed }}$ represents weed infested plot.

\section{Results and Discussion}

\subsection{Impact of Time of Weeding on Tobacco Growth}

3.1.1. Effect on Stalk Height. There were no significant differences $(P>0.05)$ among the 5 treatments for stalk height at 5 W.A.P. The control treatment showed the highest mean stalk height $(9.88 \mathrm{~cm})$ followed by the treatment that was weeded at 2 W.A.P $(9.05 \mathrm{~cm})$. Although there was effective competition in other treatment excluding the control as shown by the RCI values, the competition was less as compared to the competition intensity observed from the RCI values at 6 and 7 W.A.P. As the plant developed, there were still no significant differences $(P>0.05)$ at 6 W.A.P among the 5 treatments. The RCI values observed at this stage had increased of all the treatments showing an increase in competition intensity on all plants exposed to competitive weed density environment. These results observed in this study on the competitiveness of weeds on tobacco growth were similar to those observed by Aguyoh and Masiunas [15]. The increasing of weed density promoted a reduction in the dry bean production, reaching losses sometimes greater than $50 \%$, for the highest densities.

Significant treatment differences $(P<0.05)$ were observed among the treatments at 7 W.A.P which was due to an extensive competitive environment $(\mathrm{RCI}>0)$ as observed in unweeded treatment showing an increase of RCI value from 0.447 to 0.59 . The plants that were in the control treatment were exposed to a competitive free environment $(\mathrm{RCI}=0)$ because the RCI was constant at zero from 5 W.A.P to 7 W.A.P. However there were no significant (L.S.D $=7.60$ ) differences between the control $(28.66 \mathrm{~cm})$ and the treatment that was weeded at 2 W.A.P $(21.59 \mathrm{~cm})$. Significant differences (L.S.D $=7.60)$ were observed between the standard practice and the treatment weeded at 6 W.A.P. Results are shown in Tables 2 and 3. 
TABLE 2: Means for stalk heights $(\mathrm{cm})$ at 5,6 , and 7 weeks after planting at Kutsaga Research Station in the 2012/2013 season.

\begin{tabular}{|c|c|c|c|}
\hline \multirow{2}{*}{ Time of weed removal (W.A.P) } & \multicolumn{3}{|c|}{ Weeks after planting } \\
\hline & 5 & 6 & 7 \\
\hline Standard practice (Control) & 9.88 & 13.5 & 28.66 \\
\hline 2 & 9.05 & 11.18 & 21.59 \\
\hline 4 & 8.41 & 10.56 & 18.85 \\
\hline 6 & 7.66 & 9.97 & 15.82 \\
\hline Unweeded & 5.21 & 7.46 & 11.74 \\
\hline Significance of F & NS & NS & $* * *$ \\
\hline L.S. $D_{0.05}$ & - & - & 7.06 \\
\hline $\mathrm{CV}(\%)$ & 31.70 & 24.80 & 25.50 \\
\hline
\end{tabular}

*** Denote significance at $P<0.05$, NS: not significant at $P>0.05$.

TABLE 3: The intensity of the effect of size of competition on stalk heights at 5,6, and 7 weeks after planting.

\begin{tabular}{lcccccc}
\hline $\begin{array}{l}\text { Time of weed removal } \\
\text { (W.A.P) }\end{array}$ & \multicolumn{5}{c}{ RCI and stalk height } \\
\hline Standard practice & 0 & 9.88 & 0 & 13.5 & 0 & 28.66 \\
2 & 0.084 & 9.04 & 0.172 & 11.18 & 0.247 & 21.59 \\
4 & 0.149 & 8.41 & 0.218 & 10.56 & 0.342 & 18.85 \\
6 & 0.225 & 7.66 & 0.262 & 9.97 & 0.448 & 15.82 \\
Unweeded & 0.472 & 5.21 & 0.447 & 7.46 & 0.590 & 11.74 \\
\hline
\end{tabular}

RCI: relative competition intensity; S.H: stalk height; W.A.P: weeks after planting.

3.1.2. Effect on Leaf Area. Leaf area at 9 W.A.P showed significant treatment differences $(P<0.05)$ which was due to treatment effects at early stages of the crop. The treatment that was weeded at 2 W.A.P $(20.25 \mathrm{~cm})$ and weeded at 4 W.A.P $(24.32 \mathrm{~cm})$ showed no significant difference (L.S.D $=18.59)$ from the control $(35.20 \mathrm{~cm})$, although the treatment that was weeded at 4 W.A.P showed a higher leaf area which also indicated the appropriate time of weed control in tobacco basing on this study. Maw and Mullinix [16] reported that leaf area influences biomass production and yield of crop plants. Tobacco high yields are mainly attributed to the significant improvement in leaf areas as a result of increased leaf widths and lengths, and most of the broad types tend to produce a balanced proportion of market desirable dark and light colored cured leaf [17].

As the crop developed, a same trend on the results of leaf area was observed from 9 W.A.P to 11 W.A.P where significant differences $(P<0.05)$ among the treatments on leaf area were also observed at 10 W.A.P. The unweeded treatment was the lowest $(22.75 \mathrm{~cm})$, and there was no significant difference (L.S.D $=14.75)$ from treatment that was weeded at 2 W.A.P $(34.34 \mathrm{~cm})$ and treatment that was weeded at 6 W.A.P $(38.94 \mathrm{~cm})$. This indicated that weeding at 2 W.A.P was too early because of development of a competitive weed population from 2 W.A.P to 8 W.A.P when total weed removal was done. As the experiment advanced to 11 W.A.P, significant treatment differences $(P<0.05)$ among the treatments on leaf area were also observed. The
TABLE 4: Means for leaf area at 9, 10, and 11 weeks after planting at Kutsaga Research Station in the 2012/2013 season.

\begin{tabular}{lccc}
\hline Time of weed removal (W.A.P) & \multicolumn{3}{c}{ Weeks after planting } \\
\hline Standard practice & 35.20 & 45.79 & 49.87 \\
2 & 20.25 & 34.34 & 39.07 \\
4 & 24.32 & 38.94 & 44.50 \\
6 & 7.24 & 27.39 & 35.63 \\
Unweeded & 3.01 & 22.75 & 30.32 \\
\hline Significance of F & $*$ & $* *$ & $* * *$ \\
LSD & 18.59 & 14.75 & 10.74 \\
CV $(\%)$ & 69.32 & 8.30 & 17.4 \\
\hline
\end{tabular}

${ }^{*},{ }^{* *}$, and ${ }^{* * *}$ denote significance at $P<0.05,0.01$, and 0.001 , respectively. NS: not significant.

control had a higher leaf expansion measurement compared to the treatment that was weeded at 2 W.A.P $(39.87 \mathrm{~cm})$, and treatment weeded at 4 W.A.P $(44.50 \mathrm{~cm})$ showed no significant difference $(P>0.05)$ from the control. Results on the effect on leaf area are shown in Table 4.

3.1.3. Impact of Time of Weeding on Yield. There were no significant differences $(P>0.05)$ among the treatments on yield recorded from reap 1 . This was mainly due to a few numbers of leaves harvested at this stage, and for treatments weeded at 6 W.A.P. At this stage the unweeded treatment had more harvested leaves due to false ripening. Significant differences $(P<0.05)$ were noted among the treatments at reaps 2 and 3 . The treatment weeded at 4 W.A.P was significantly higher (L.S.D $=192.8$ ) than the treatment weeded at 2 W.A.P. The same trend was also observed on the yield recorded for reap 3. This support the suggested appropriate time of weeding in tobacco basing on this study as indicated from the results on leaf area in this study. The stage of yield reducing competition which was observed to be from 4 W.A.P by Cousins [18] also supports the appropriate time of weeding suggested from the yield results observed from this study. This study also indicated the relationship on leaf area and yield of tobacco. High weed densities in treatment weeded at 2 W.A.P and 6 W.A.P and the unweeded treatment contributed to lower yields recorded. Weed density increase resulted in leaf yield reduction. The results are shown in Table 5.

\section{Conclusion}

Based on results of this study, the most important stage to avoid yield reduction was from 4 W.A.P to the topping stage 9 W.A.P. The critically damaging period of weed competition can be effectively countered by weed control in early stages of weed germination and growth, although subsequent cultivation may be required to ensure continued control of all germinating weeds. In situation where labor shortages are experienced weed control practises should be done at 4 W.A.P. 
TABLE 5: Mass at untying first reaping, second reaping, and third reaping (KG/HA).

\begin{tabular}{lcccc}
\hline \multirow{2}{*}{ Time of weed removal (W.A.P) } & \multicolumn{4}{c}{ Reap } \\
& Reap 1 & Reap 2 & Reap 3 & All groups \\
\hline Standard practice (control) & 153.53 & 474.86 & 459.71 & 1088.1 \\
2 & 74.08 & 267.97 & 220.9 & 562.95 \\
4 & 73.67 & 460.5 & 364.71 & 898.88 \\
6 & 84.15 & 294.33 & 289.0 & 667.48 \\
Unweeded & 77.56 & 234.38 & 211.29 & 523.23 \\
\hline Significance of F & NS & $*$ & $*$ & $*$ \\
L.S.D & - & 192.8 & 143.6 & 270.80 \\
CV $(\%)$ & 63.3 & 41.5 & 28 & 25 \\
\hline
\end{tabular}

${ }^{*}$ Denote significance at $P<0.05$.

NS: not significant; W.A.P: weeks after planting.

\section{Acknowledgments}

The authors would like to acknowledge the Tobacco Research Board Zimbabwe (T.R.B) for the assistance rendered during this study, for allowing me the opportunity to use the facilities of the T.R.B, and for funding this study and Dr. Walter Manyangarirwa of Africa University for helpful discussion.

\section{References}

[1] J. L. Stocks, "Flue-cured tobacco production in Zimbabwe," CORESTA Zimbabwe, pp. 205-209, 1994.

[2] FAO, Issues in the global tobacco economy, Food and Agricultural Organization of the United Nations of Rome, 2003.

[3] S. Mabasa, A. M. Rambakudzibga, O. Mandiringana, C. Ndebele, and F. Bwakaya, "A survey of maize production practices in three communal areas of Zimbabwe," in Paper Presented at the Rockefeller Soil Fertility Network Meeting, p. 28, Kadoma, Zimbabwe, July 1995.

[4] A. S. Adegoroye, O. A. Akinyemiju, and F. Bewaji, "Weeds as a constraint to food production in Africa. Management and the African farmer," in Proceedings of the ICIPE/World Bank Conference on Integrated Pest Management in Africa, ICIPE Science Press, 1989.

[5] R. W. Wilson, "Effects of cultivation on growth of tobacco," Tech. Rep. 116, Agricultural Experiment Station, Raleigh, NC, USA, 1995.

[6] A. Niell, A Windmill Guide to Controlling Losses in Tobacco Production, Windmill Private, 1996.

[7] G. C. Klingman, "Weed control in flue-cured tobacco," Tobacco Science, vol. 11, pp. 115-119, 1967.

[8] I. O. Akobundu, "Weeds in human affairs in sub-Saharan Africa: implications for sustainable food production," Weed Technology, vol. 5, pp. 680-690, 1991.

[9] A. M. Rambakudzibga, A. Makanganis, and E. Mangosho, "Competitive influence of Eleusine indica and other weeds on the performance of maize grown under controlled and open field conditions," Zimbabwe Agricultural Journal, vol. 75, pp. 14$18,2000$.

[10] S. Z. Knezevic, S. P. Evans, E. E. Blankenship, R. C. Van Acker, and J. L. Lindquist, "Critical period for weed control: the concept and data analysis," Weed Science, vol. 50, no. 6, pp. 773$776,2002$.
[11] V. Vincent and R. G. Thomas, An Agricultural Survey of Southern Rhodesia Part I: An Agroecological Survey, Government Printers, Salisbury, UK, 1960.

[12] K. W. Nyamapfene, Soils of Zimbabwe, Nehanda Publishers, Harare, Zimbabwe, 1st edition, 1991.

[13] J. B. Grace, "On the measurement of plant competition intensity," Ecology, vol. 76, no. 1, pp. 305-308, 1995.

[14] D. E. Goldberg, T. Rajaniemi, J. Gurevitch, and A. StewartOaten, "Empirical approaches to quantifying interaction intensity: competition and facilitation along productivity gradients," Ecology, vol. 80, no. 4, pp. 1118-1131, 1999.

[15] J. N. Aguyoh and J. B. Masiunas, "Interference of redroot pigweed (Amaranthus retroflexus) with snap beans," Weed Science, vol. 51, no. 2, pp. 202-207, 2003.

[16] B. W. Maw and B. Mullinix, "Comparing six models of various complexities for calculating leaf area from measurements of leaf width and length," Alteration of Leaf Shape in Field Tobacco Science, vol. 36, pp. 40-42, 1992.

[17] R. T. Garvin, "Flue cured Tobacco yield estimation in crop research," Zimbabwe Science News, vol. 19, no. 5-6, pp. 65-67, 1985.

[18] L. T. V. Cousins, The effects of weed competition on flue-cured tobacco yield and quality (Nicotiana tabacum) [Ph.D. thesis], Department of Agriculture, University of Rhodesia, 1979. 


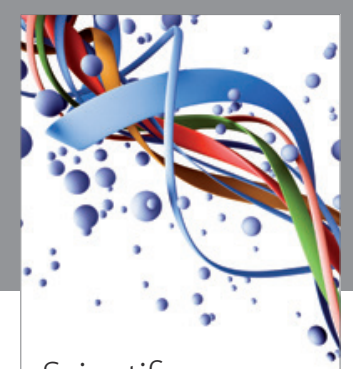

Scientifica
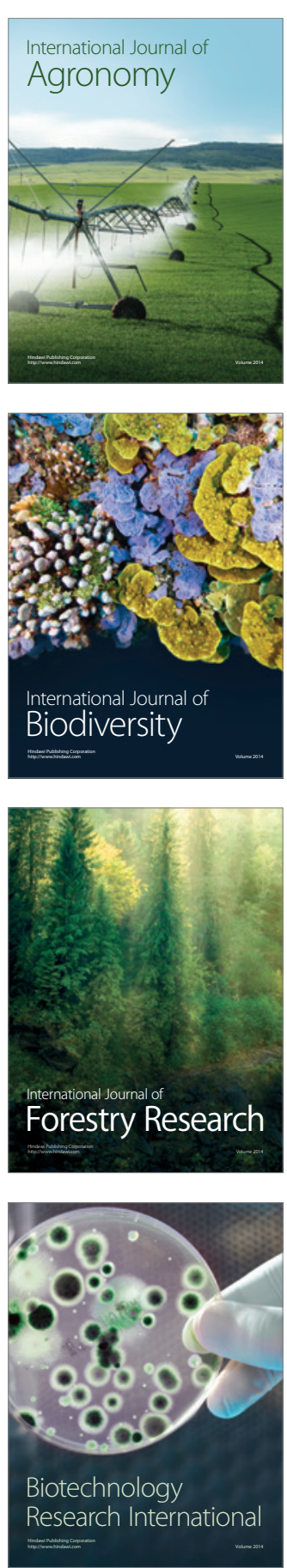
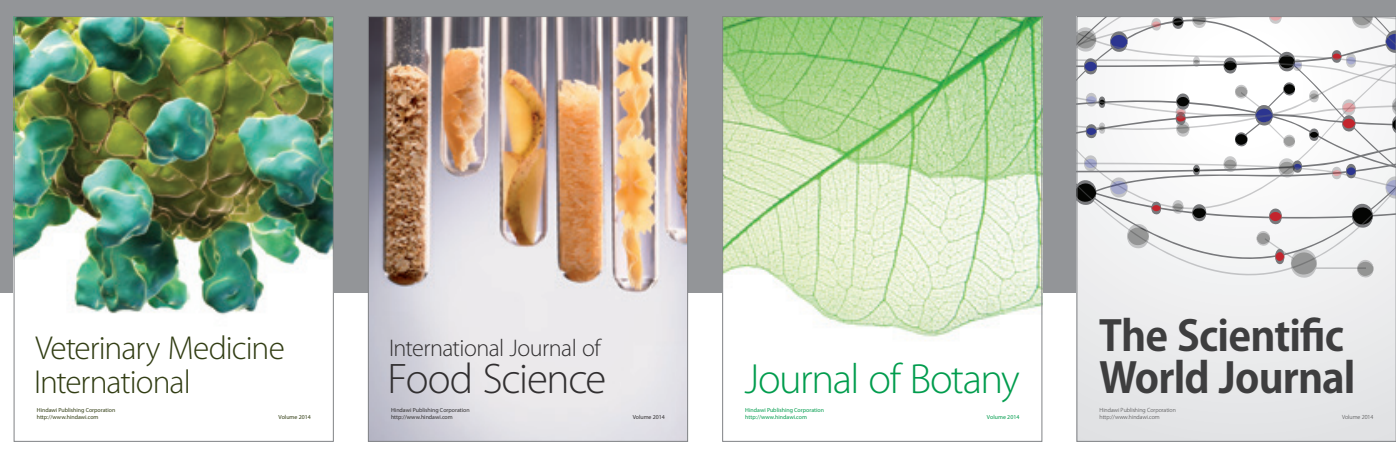

The Scientific World Journal
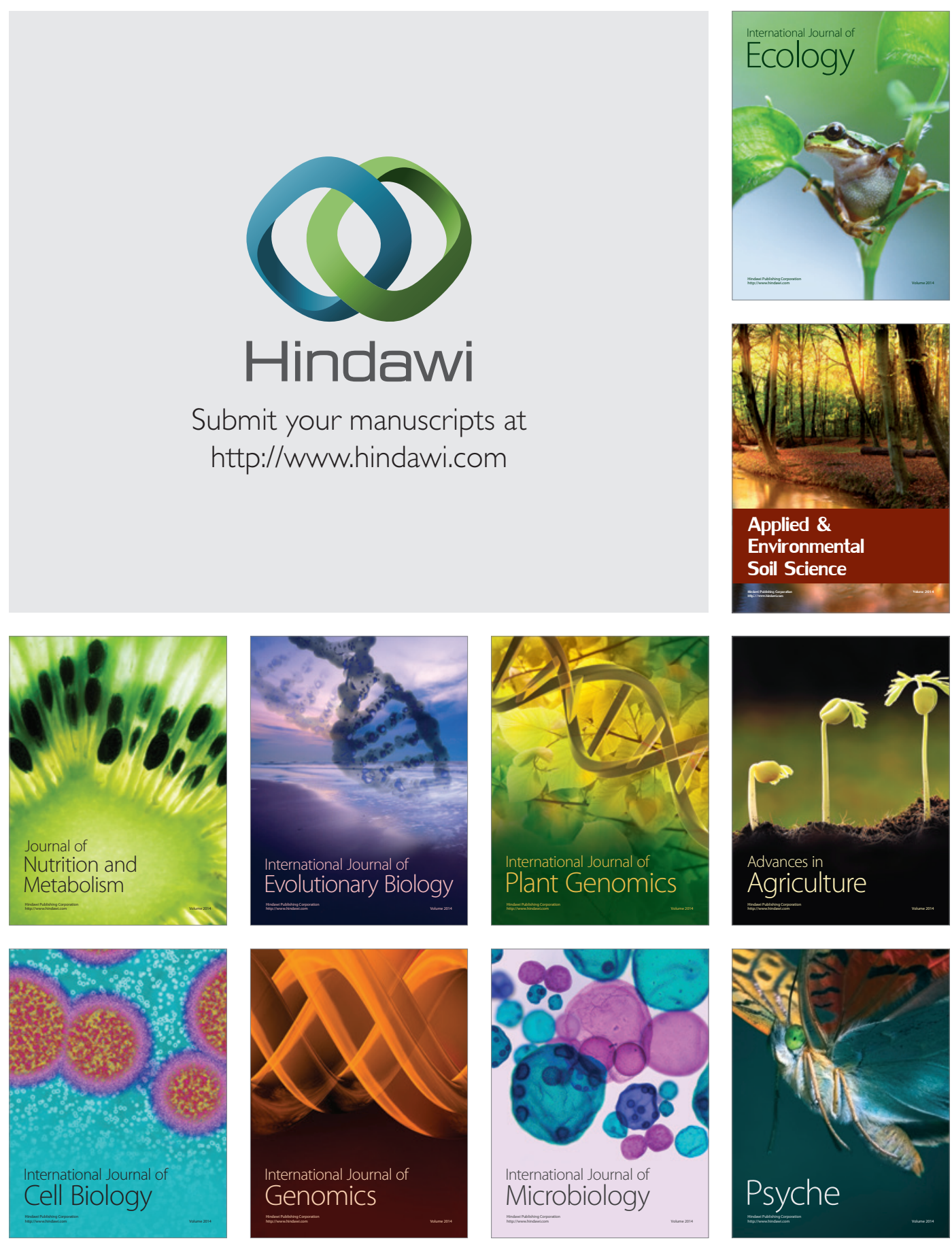